\title{
POTENTIAL PERSONS AND THE WELFARE OF THE (POTENTIAL) CHILD TEST
}

\begin{abstract}
This paper considers the theoretical basis of 'the welfare of the child' as it exists in the Human Fertilisation and Embryology Act 1990 (as amended by the 2008 Act of the same name). It will be argued that potential persons, that is persons who do not yet exist, have no claims, interests or standing that can restrict the actions of actual persons. This claim will be based upon the necessity of existence before things can be said to affect a person. As persons are the subject for whom good and bad apply, actions which establish the preconditions for their existence cannot be subjected to considerations of the effect on the potential person. This is because potential persons are not affected by actions, but are the consequence of actions. Prospective parents, for example, should not be prohibited from having disabled offspring on the basis of the effect on the child, as different decisions relating to that child will change which persons exist, and thus the necessary preconditions for value will change. Based upon this logical framework it will be argued that only the interests of actual persons can constrain the actions of those involved in reproduction. Thus, the Human Fertilisation and Embryology Act's formulation of the welfare test must be repealed and only the interests of prospective parents and other actually existing people should be capable of constraining reproduction.
\end{abstract}

Keywords: genetic, person, embryo, existence, welfare test

\section{INTRODUCTION}


Developments in fertility treatment and artificial reproductive technology (ART) have created an unprecedented level of control of the process of reproduction. Prospective parents now have many options for fulfilling their desire to have children; everything from artificial insemination to in vitro fertilisation, from adoption to surrogacy and possibly through genetic modification. In response to the development of these technologies the UK government established the Committee of Inquiry into Human Fertilisation and Embryology (1982-1984) to consider the implications and responses to these emerging reproductive technologies. The Committee then produced a report (also known as the Warnock Report) which then formed the basis for a draft bill that was passed into law as the Human Fertilisation and Embryology Act 1990 (hereafter the 'HFE Act'). This Act created the Human Fertilisation and Embryology Authority which has regulatory oversight of all fertility treatment and reproductive services (although this regulatory function may be transferred to the Care Quality Commission and others ${ }^{1}$. The HFE Act contained a provision in section 13(5), which requires that "the welfare of any child who may be born as a result of the treatment" be taken into account ${ }^{2}$. It is the welfare of the (potential) child test as it exists in the HFE Act that is questioned and critiqued in this article.

It will be argued that the welfare test when applies to the potential child is problematic because it is too burdensome on prospective parents (hereafter parents); both because it requires that the parents are vetted to determine whether they are 'suitable' and because the test imposes obligations on the parents for the sake of the child (most noticeably in the case of disability). Moreover, if these obligations are

\footnotetext{
${ }^{1}$ Human Fertilisation and Embryology Authority, 'Statement: HFEA responds to government's proposals on the future of the HFEA', 2012 .

${ }^{2}$ Human Fertilisation and Embryology Act 1990 s.13(5).
} 
followed then the child will never come to exist and this in effect requires that parents act for a never existing child. Equally, if genetic modification technology became available it would require that parents use it to improve the welfare outcome of the potential child. The welfare of the potential child test therefore creates a discriminatory system in which those who cannot reproduce naturally are doubly penalised; they must prove their competence to be parents, and the test creates strong prejudice against parents who want to produce a child who has, or might have, a disability. These restrictions thus need to be strongly explicated in order to justify the imposition of such onerous obligations on parents and also the denial of services to those who may not wish to undergo genetic testing for disability or those who may want to have a child with a particular disability.

The justification for restricting access to reproductive technology, as shown by section 13(5), is the "welfare of any [potential] child who may be born"3. It is the benefits and welfare that accrue to the potential child that justify considering the conduct of the parents and the risk of disability. However, it will be argued that consideration of the welfare of the potential child is not valid because it is incorrect that a child can be benefitted or harmed by actions that cause them to exist; that is, actions which constitute the person cannot affect that same person because their existence is a necessary pre-condition for them to benefit or harmed. As David Heyd states: "they [potential persons] do not meet certain preconditions of existence and identity" ${ }^{4}$ which would allow them to be the object of beneficence or maleficence. Thus the welfare of the potential child cannot be the basis of claims regarding benefiting or harming the child, the considerations that are

\footnotetext{
${ }^{3}$ Act. s.13(5).

${ }^{4}$ D. Heyd, Genethics: Moral Issues in the Creation of People (University of California Press: Oxford, $1^{\text {st }}$ edn, 1992) 36 .
} 
used to restrict access to reproductive technology and service are unfounded. This becomes even more apparent when the denial of access to reproductive technology services means that no child ever exists. As the child never exists it is logically impossible for them to 'benefitted' or 'harmed' but this also applies in reverse, a child who does come to exist cannot be benefitted or harmed either. This is what Heyd calls "full symmetry" between benefitting and harming in both cases of not bringing, and of bringing a child to exist.

Consequently, the law relating to reproductive technology and services will have to be reformed by removing the 'welfare of the potential child' test from the HFE Act because it is based upon of a concept of harm in which harm is impossible. Using the example of genetic modification, the implications of this test for what is permissible will be explored, and the scope of parents' decisions will be explicated. These implications do not however suggest that parents should have unrestricted access to these services, (because resource constraints and distributive justice are also involved) but they do mean that parents cannot be denied access to genetic modification services on the basis of harming a child who will never exist; and who cannot be harmed if they do exist. Only on the basis of the impact on other actual persons and member of the socio-political unit can claim to be affected by allowing parents to have disabled offspring. Furthermore, the welfare of the child once it actually exists is covered by the 'welfare of the child test' found in section one of the Children Act 1989, thus providing a means for dealing with parents if they are abusive to their offspring. Society could therefore decide that people who want to be parents have to conform to a certain standard of conduct and comport themselves in a certain manner, but this would have to apply to all parents (whether using reproductive technology or conceiving naturally) because the determination and judgement is located in the parents themselves. The arguments that will now be presented will support the final recommendations of this paper; namely that the welfare 
of the potential child test in the HFE Act must be removed and that the determination of access to reproductive services should be based upon the effect on actual persons, or a standard applicable to all.

\section{THE WELFARE OF THE (POTENTIAL) CHILD TEST}

Under section 13(5) of the HFE Act, the welfare of the child test operates as follows:

"A woman shall not be provided with services ... unless account has been taken of the welfare of the child who may be born as a result of the treatment (including the need of that child for supportive parenting), and of any other child who may be affected by the birth"

The HFE Authority's $8^{\text {th }}$ Code of Practice guidance notes on the welfare of the child state that the "factors to be taken into account during the assessment process" of the parents include the risk of "serious physical or psychological harm or neglect" 5 and "where the medical history indicates that any child who may be born is likely to suffer from a serious medical condition" ${ }^{\prime \prime}$. Subsections 13(9) and 13(10) of the Act, inserted by the amending 2008 Act, state that "embryos known to have" a serious disability, illness or "other serious medical condition" "must not be preferred to those [embryos] that are not known to have such an abnormality"' . Together, these legislative provisions and code of practice notes make two things clear; that the conduct of parents is subject to scrutiny and that parents cannot select for an embryo that has a disability, but can reject

\footnotetext{
${ }^{5}$ Human Fertilisation and Embryology Authority, Code of Practice, $8^{\text {th }}$ edn, 2009, s.8.10 .

${ }^{6}$ Code of Practice s.8.10(b)(iii).

${ }^{7}$ Human Fertilisation and Embryology Act 2008 s.14.
} 
an embryo on that basis. As both sets of considerations operate under the welfare of the (potential) child test, it is clear that the reasons and justifications for these considerations are rooted in assumptions that they are harmful to the child's welfare.

Thus a positive determination that the potential child will be subject to abuse or neglect, or will have a serious disability, will prevent the parents from accessing reproductive services, frustrating in its entirety their interest and desire to have children. This places parents in the invidious position of not being able to have children without medical help, but also of being judged both on their characteristics and their choice of foetus. Moreover, if any of these judgements go against them then the child they would supposedly be harming would never even exist. Persons who do not exist cannot be harmed because their non-existence precludes anything affecting them in any sense. We will come to the impossibility of harming potential persons in due course, for now we can note the effects of the current legal regime. Firstly, by requiring those who seek reproductive services to prove their ability to be 'good' parents those who are already at a severe disadvantage are further penalised. The institutional burden imposed on them, which is not imposed on other members of society, could be construed as an unacceptable interference with the parent's reproductive autonomy. Reproductive autonomy could be found under Articles 8 and 12 of the European Convention of Human Rights and thus would need to be strongly justified. The discussion of reproductive autonomy, and whether there is a right to it, is beyond the scope of this paper. However, it should be noted that the arguments presented here mean that the requirement of proving parental capability would not make sense on the basis of the potential child's welfare. Requiring proof of parenting competence could be justified if applied to all potential parents, but it would have to be a universal requirement. Thus the justification for the burden of proving parental capability would be moved solely to the parents and would not be related to the potential child. 
More importantly though the demand that disabled embryos are not to be preferred and the fact that disability counts against the potential child's welfare implies that there is an obligation not to have disabled children. This obligation can be inferred because the logical corollary of the statement that disabled foetuses "are not be preferred" ${ }^{8}$ is that non-disabled foetuses are to be preferred. This restriction on having disabled offspring removes the choice of parents and mandates what they can and cannot do. Furthermore, if genetic modification could improve the potential child's 'welfare' then it may be required of parents to use genetic technology because the basis of the constraints are the potential child's interests which (as shown by the restrictions imposed on parents by the HFE Act now) are strong enough to force parents to refrain from acting (and thus logically require them to act) in certain ways.

As this is justified on the basis that disability is against the potential child's welfare then if this is not the case the preference for non-disabled offspring and the constraint imposed on the parents must be removed. Parents could therefore not be prevented from having disabled offspring if they so wished, at least on the basis that it is against the child's interests. The welfare of the potential child then is the source of the problems that are thrown up by applying the welfare test to those seeking access to reproductive technology; namely that the potential child welfare acts as justification for restricting who can have children and under what conditions when in fact the child's welfare cannot be affected by any decision made. It is to this person-affecting dilemma to which we now turn.

III. WELFARE OF THE CHILD: WHAT CHILD?

\footnotetext{
${ }^{8}$ Human Fertilisation and Embryology Act 2008 s.14.
} 
The fundamental problem with the welfare of the (potential) child test is that welfare by definition is for someone but in this case the person concerned does not exist. The welfare of the child test, contained in the HFE Act s.13(5), explicitly includes the concept of harm to the potential persons, thus identifying the potential child as the subject affected. This is, however, a logical impossibility because the necessary condition for welfare to be considered, that is the existence of a person, is not met. Moreover, if the potential person's welfare is considered to be at risk, then they will never come to exist so they will never benefit from this welfare decision. As welfare is person-affecting it is predicated upon the existence of someone for whom welfare is for, but this person must therefore be able to value or disvalue things which affect their welfare; that is, they must be a 'valuer'. As value cannot exist without valuers (in this case, welfare cannot exist without being for someone) then "valuers have the unique status as the condition of there being any value" . In the cases under discussion (parents seeking reproductive services to produce a child) the only valuers for whom the decision can be of value are the parents. The potential child therefore cannot have a welfare that can be affected when it is the decision which will determine whether it exists or not.

This seems clear, and highlights the fact that deciding against the existence of potential person cannot count as beneficial to them. Obviously it could be beneficial to the parents as existing valuers, because they would not have the burden of raising a (disabled or non-disabled) child, and it could be beneficial for other actual members of society, for example, due to the consumption or distribution of healthcare resources. But it is painfully obvious that it cannot be beneficial to the potential person when they will never exist. For example, genetically modifying an embryo so that it no longer has a genetic disability would not benefit it, because the decision to genetically modify would

\footnotetext{
${ }^{9}$ Heyd, People at 117.
} 
constitute the potential person; that is, it would be a decision prior to and determinative of their existence. There is no basis for the claim that offspring are harmed by genetic modification when it is that genetic modification which causes them to exist.

Furthermore "equally and for the same reasons, we cannot hold the child to be an object maleficence" ${ }^{\prime 10}$. Just as a valuer needs to exist before they can benefit from things so they have to exist before they can be harmed by things. For example, a potential disabled child cannot be harmed by being brought into existence. Thus "potential people have equal standing regarding our beneficence and our nonmaleficence" ${ }^{, 11}$ which is to say they have no standing. However this also means that creating new valuers is itself of no value independent of those valuers who already exist, there thus can never be any presumption to implant an (or any) embryo. This also means that there can never be a presumption against implanting an (or any) embryo. It is only on the basis of the interests of actual persons, the parents, that decisions regarding offspring can be made.

Once the potential person does exist then they can be affected by the circumstance in which they exist. The necessary pre-condition for value (harm and benefit) to attached someone have been met (by their existence) and from there onwards they possess interests because they being to form a biographical life. A biographical life consists of the actions, desires, projects and decisions that make up a life ${ }^{12}$; that is the components that give a life consistency. It should thus be self-evident that an existing child has interests that can be accounted for and protected, and these post-existence effects can form the basis of welfare decisions. At this point the Children Act 1989 section one would be applicable and which would protect the actually existing child,

\footnotetext{
${ }^{10}$ Heyd, People 109.

${ }^{11}$ Heyd, People 115.

12 Statement by John Harris (Personal communication 12 April 2013).
} 
further eroding the purpose and need for the welfare test in the HFE Act. The case of disability is a good example of the argument outlined above.

If an embryo has the genetic characteristics of a being disabled the HFE Act considers the disability to count as the basis of rejecting that embryo, and prohibits selecting that embryo when a non-disabled embryo is available ${ }^{13}$. This is so even though the offspring would not actually come into existence because the embryo has been rejected and thus no subject would ever exist to benefit or suffer harm from the decision taken. However, this also applies to a decision to allow the disabled embryo to develop to term, because the potential person must exist before the person-affecting nature of value can be present. In such cases (rejection, acceptance or modification of the disabled embryo) the potential person cannot be affected by the decision taken, but the parents can. Thus, it is their interests which are relevant when deciding which embryo to implant and it is up to them to determine whether having offspring with a disability is against or in their interests. Once a child exists (whether disabled or not) then the pre-condition for value to be for them has been met and they will possess interests that can benefited or harmed. The welfare of the child test under the Children Act will now apply and judgements regarding the child's welfare can now be made, thus forming the basis of decisions and actions about the child's upbringing and care.

As noted throughout this paper, the basis of removing the potential person (the child who may result) from consideration is the necessity of their existence before they can be harmed or benefitted. This applies equally to negative constraints (such as not selecting certain embryos) and positive requirements (such as genetically modifying an embryo). Consequently it is impossible to maintain the HFE concept of the welfare of

\footnotetext{
${ }^{13}$ Human Fertilisation and Embryology Act 1990, Human and Fertilisation and Embryology Act 2008, Human Fertilisation and Embryology Authority Code of Practice, 8th edn, 2009.
} 
the offspring who results from the treatment because potential people have no welfare to speak of. The welfare of the (potential) child test should therefore be abolished and the consideration of the potential child removed as a factor for consideration when deciding on distributing reproductive technology and services. Any restrictions or constraints imposed upon parents would then have to be based upon the impact on actual persons which would include the parents seeking reproductive aid and the other actual members of their socio-political unit (more on this later). The general form of the test found in the Children Act, with its focus on existing offspring, would, of course, retain its applicability to offspring once they exist.

We can thus see how this change would eliminate the restriction on parents when it comes to the selection of different embryos for implantation. Next we will consider an alternative to the person-affecting approach; impersonalism. If there is an alternative to the claim that welfare must person-affecting, then this may undermine the claim that welfare must be for someone. This alternative, however, can only be based on a nonperson-affecting account; namely impersonalism.

\section{IMPERSONALISM: THE ALTERNATIVE TO THE PERSON-AFFECTING}

\section{APPROACH}

As has been made clear throughout this paper the welfare of the (potential) child is logically unsustainable if welfare is attached to a subject. Thus, if welfare can be framed in such a way that it does not attach to a subject, then this would offer another method for regulation to incorporate the welfare test. To be clear, impersonalism here is not "a common standard" 14 that is good for everyone; as this would simply be claiming that there is some $x$ which is good for all subjects who exist. It would thus still be tied to the actual

\footnotetext{
${ }^{14}$ Heyd, People 82
} 
existence of people but would simply be a claim that $x$ is good for all of them. This obviously would not be an alternative to, or an answer to, the argument set out above because it would still require that a person exist for them to benefit from the common standard. Here, impersonalism is used to mean the existence of value as a feature of the world; that is value is independent of persons and attaches "to the world" 15 . This stance would thus identify what is 'good' and claim that the more of this good, the better because it is as a feature of the world that it has value, not as it relates to persons (if they exist).

So what might an impersonalist approach look like? Julian Savulescu argues for an approach in which the offspring "who is expected to have the best life, or at least as a good as life as the others" ${ }^{\prime 16}$ should be chosen. We would therefore not select a disabled foetus because it would not have the best expected life. However as Rebecca Bennett puts it "This individual is born in this impaired state or not at all" is between the existences of different potential people and on a person-affecting account this raises the same problems outlined above. Consequently, we could not say it is better for those who will not exist, as this would be to take a person-affecting perspective. Of course on a person-affecting view we could say that it is better for those of us who actually exist that this particular potential person does not exist. For Savulescu's comparison to work it would have to be based upon impersonal criteria, particularly as the existence of each potential person is mutually exclusive of the others. In order to avoid relying on the effect on any people, what we would have to say is that the world is a better place with those particular potential person in it rather than these other potential

\footnotetext{
${ }^{15}$ Heyd, People 80

${ }^{16} \mathrm{~J}$ Savulescu 'Procreative Beneficence: why we should select the best children' (2001) Bioethics 413, 413.

${ }^{17}$ R Bennett 'The Fallacy of the Principle of Procreative Beneficence' (2009) Bioethics 263, 267.
} 
persons because those we allow to exist will contribute more 'good' (in this case the best lives) to the state of the world. That is the world is better off than with alternative persons in it because they add to the total 'good' in the world. Alternatively, it could be that impersonalism is based upon being the right kind of person (i.e. being human consists of suffering and limitation $\left.{ }^{18}\right)$.

The essential problem with impersonalism is that it "sacrifices the utility of individuals to the promotion of the impersonal value of the overall good"19. In other words, whatever the 'good' is, people are merely a means to produce the good, and thus individuals are always expendable. This means that people are not relevant beyond the production of the good, for example, if health was the primary good (as suggested in Savulescu's scenario) then all parents could be forced to undergo whatever procedure best produced health, as long as the cost in the health of the parents was outweighed by the gain in the offspring. If impersonalism is based upon creating the right kind of people then this balancing act would be unnecessary; it would only be when the wrong kind of offspring were to be produced that parents would have to take measures to prevent it whatever those measures are. Now it is obvious that if impersonalism is correct, then the subjugation of individuals to the production of the good or to the creation of the right kind of person, is not only permissible but an obligation. The restrictions imposed upon individuals could thus be justified.

But impersonalism is not a sound or coherent theory because the identification of the 'good' or the right kind of people unavoidably presupposes the existence of valuers. The good that forms the basis of impersonalism (whatever it is) are "by necessity of

\footnotetext{
${ }^{18}$ L Kass, 'Ageless Bodies, Happy Souls: Biotechnology and the Pursuit of Perfection' (2003) The New Atlantis 9.

${ }^{19}$ Heyd, People 57.
} 
actual" ${ }^{20}$ persons. Without actual persons, that is valuers, it is impossible to differentiate between different conceptions of the good because a world without persons is valueless. Otherwise anything could be good, even the murder of humans could be justified on the basis that it is more natural for a predator species to behave in such a manner and thus promoting the good of the natural world. Thus the existence of persons, who can identify the good, are a pre-requisite for impersonalism to work, but this is the very basis that impersonalism claims to do without. More to the point, impersonalism itself gives all individuals a reason to reject it because it could impose upon them a good which they do not find to be good. Impersonalism can therefore only work at one level of discourse; namely the identification of objective goods for a particular reference group. It cannot be used to justify the existence of members of that reference group because the identification of value to potential people is impossible. Furthermore the identification of a good to which persons are subservient is not possible, because 'good' has to relate to the person or persons affected.

Thus we cannot resort to impersonalism to solve the conundrum of impossibility of the child who may result possessing welfare interests because it provides reasons for individuals to reject it by reducing persons to mere producers of a good and thus justifying any restriction or interference which promotes this good. It is also conceptually incoherent as the good cannot be identified without presupposing the existence of the reference group (valuers). Once the reference group exists then the conception of the good becomes person-affecting, as only by tying good to valuers does it make sense to differentiate between potential goods. The arguments pertaining to the illogical and impossible conception of welfare for a potential person remain valid and cannot be replaced with impersonalism. We therefore have to accept that the welfare of the potential child

\footnotetext{
${ }^{20}$ Heyd, People 63.
} 
test is unsustainable and that the law is wrong to have such a test because it is factually impossible for the test to have any effect on the person it supposedly protects. The only option left is to remove the test completely. This does not however mean that parents have or should have unfettered decision-making powers over reproduction, but it does mean that such restrictions must be based upon the interests of actual persons; in this case the parents, and the other members of their socio-political unit. It is to this consideration that we now turn.

\section{THE DECISIONS OF PROSPECTIVE PARENTS}

Having dispensed with the welfare of the potential child test we need to decide if and on what basis the reproductive decisions of prospective parents could be constrained. As the preceding section pointed out, without the welfare test and the requirement that the decisions take a person-affecting form means that reproductive "genesis choices ... should be guided exclusively by reference to the interests, welfare, ideals, rights and duties of those making the choice" ${ }^{21}$. Those who are making the choices are the "generators" of the (pro)creative effort and, as it is their interests that are of concern, Heyd calls this theory of their predominance "generocentrism",22. Generocentric theory will form the foundation of the new reformed approach to reproduction, specifically in the case of parents utilising reproductive technology and services where the decisions of the parents are contingent upon the acceptance of those providing the service for the decisions to take affect. Artificial reproduction therefore provides a case in point where the interests of other actual persons and the interests of parents intersect.

\footnotetext{
${ }^{21}$ Heyd, People 96.

${ }^{22}$ Heyd, People 96.
} 
From the arguments set out throughout this article culminating the generocentric theory, there can be no restrictions imposed upon parents from the perspective of the potential child. Parents should therefore have greater control over the reproductive process unconstrained by the supposed impact on the potential child. What is of interest here is what possible constraints there might be for the parents in the absence of the welfare of a potential child. As pointed out earlier, any such constraints would have to be based upon either the interests of other people or upon a requirement for the parents to meet a standard of conduct. Given the emphasis on the person-affecting nature of actions, an approach grounded upon the interests of other people is the only justification for restricting the actions of parents, but this could of course take the form of a standard of conduct. However, we will avoid becoming encumbered by discussions between the relative merits of the different forms the restrictions may take. We shall instead focus on the effects which would justify imposing the constraints.

Some examples are; the increase of healthcare costs, ensuring genetic diversity for the gene pool, preventing hyper-aggression, improving immune systems, muscle strength, liver function, and brain functioning and so on. The justification for restraints could also relate to the kind of society that we are trying to build, whether it is strongly democratic and pluralistic with a strong sense of individualism, or whether strict conformity to a particular ideal is required or whether reproduction is considered a collective effort or interest. Given that the jurisdiction under discussion is the UK, this paper takes it as given that the constraints have to be compatible with a democratic pluralist human rights respecting society. In this case the basis of restrictions has to be proven by those seeking to restrict the actions of the parents. This would be even stricter if a formal right to reproduction or reproductive autonomy were to be created or recognised, because the restriction would also have to be necessary and proportional. 
However the decision as to whether there should be such a right is beyond the scope of this paper.

Thus it must be noted that this person-affecting approach would entail a strong form of reproductive autonomy for parents generally in the area of reproduction as the impact upon others would have to be proven. For example, if someone claims that it would be harmful to have a disabled child then they must show to what interests it is harmful; it could not be based upon simply disapproving of the choice. It is therefore plausible that only a significant interest could restrict parental decisions. Such a significant interest might be the interest of actual persons to have access to healthcare. Thus parents who choose to have disabled offspring might be constrained on the basis that the additional resource burden on the healthcare system and the subsequent effect on people's interests make the choice to have disabled offspring an unreasonable expectation for the use of public resources. It could not however be based upon the harm done to the parents themselves, because it is up to them whether the burden of raising disabled offspring is outweighed by the benefits of having a child; but it could easily be based upon the effect on others. Such a justification would bring in concerns of fair distribution of resources, safeguarding and balancing conflicting interests (and/or rights) amongst a population, population growth policy and societal aims, changes or objectives. One scenario may be that the interests of actual persons make it preferable to ensure a universally accessible standard of reproductive technology rather than a private system that only some could afford.

Other modifications however may be problematic, skin colour, for example, may be something that remains outside of parental remit not because it may create a burden or thwart the interests of others, but because allowing such a choice in a society which unjustifiably discriminates against certain skin colours may cause reproduction (and genetic modification) to be used to reinforce racism and other prejudices. Such a 
consequence could be opposed because diversity is valued by society as leading to a richer and deeper culture, because it is a superficial difference, or because the promotion of a united human governmental system or human rights culture are considered important for improving the lives of actual persons. In this case the justification could be based upon the harm done to actual persons in the sense that they would live in a society that is worse for them because it violates the basic principles or objective of society. Deciding on what may and may not be permitted is up to the socio-political unit where artificial reproduction takes place; it is beyond the scope of this paper to consider the political methods which should be used. However, in no case could it be based upon the potential person themselves, as it is impossible for them to have interests and because they are irrelevant themselves except for their value to extant persons.

Finally, imposing constraints on parents may be justified because we (that is, the rest of society) do not want them to achieve or satisfy their interests. For example, parents who want to inflict suffering and harm on a person may be prohibited from utilising reproductive technology and services because we do not want to help people satisfy their desires to act in cruel and abusive ways by creating a child. In such cases we are not saying that the child's interests would be harmed by being created for such a purpose and once they exist, their interests would justify removing the child from the parents although this may be a difficult and protracted process. Rather, we are saying that the very interest the parents seek to fulfil is prohibited and thus they cannot be permitted to achieve their goal. This would be similar to not allowing people to vandalise public or abandoned property, to torture willing 'victims' or to take class A drugs even if no one is directly harmed by such conduct. This is because some conduct is deemed unacceptable by society and those who would use reproductive technology and services to fulfil these prohibited objectives could be prevented from doing so. 
Regardless, within the UK and other democratic pluralist human rights respecting nations, the interests and decisions of the parents would be primary. This approach would therefore create a legal presumption or right in favour of permitting prospective parents to reproduce the offspring they wish, and those who wish to restrict the actions of parents would have to make their case and provide evidence of their claims. Thus the person-affecting approach does not preclude restricting the actions of prospective parents on the basis of the interests of other persons or on the basis that prospective parents should act in certain ways. This would be based on competing interests between societies, existing members and the parents. This provides the justification for judicial oversight of reproductive technology, while protecting parents from being denied access to reproductive services on the basis of the welfare of the potential child.

\section{CONCLUSION}

The fundamental argument of this paper is that potential persons have no standing (moral, ethical or legal) in relation to those who actually exist. A potential person cannot benefit from existing or not and neither can a potential person be harmed. Consequently, when it comes to reproduction, the interests of prospective parents are unconstrained by the effect of their actions on their potential offspring because actions which cause a person to exist cannot affect them. Parents are thus free to choose to have disabled, genetically modified or 'normal' offspring as they wish. The only source of restrictions on parental conduct comes from the effect of their actions on other actual persons. This approach is explicitly person-affecting which has as a pre-condition for it to apply that a person actually exists. It is this that underpins the argument that potential persons have no standing compared to the interests of actual persons, be they parents or members of society. 
The importance of this change in outlook is prompted by the welfare of the (potential) child test included in decisions about access to reproductive services by infertile couples. This is objectionable because those already experiencing difficulties in having children are further penalised by having to prove their capacity to be parents; and all this because of a potential person who cannot be affected by their actions anyway. The point at which the potential offspring becomes actual (when the child can be affected) is covered by the Children Act 1989 anyway. Thus parents have their choices, decisions and actions restricted by the interests of a being that does not exist. When we consider the impossibility of harming potential persons we can see that this is an unjustified restriction imposed upon parents which consequently should be removed. Only by taking an impersonalist non-person-affecting approach could we avoid this difficulty.

Impersonalism has however be shown to be incoherent and flawed because it is abhorrent to individuals by making them into producers of value (reducing their own interests into irrelevance) and because it presupposes the existence of valuers in order to determine and identify the value(s) that are to be produced. Note once again that this is not to say that impersonal considerations are irrelevant when considering benefits across an identified reference group, but that the very foundation of benefit, harm and value cannot be disconnected from the existence of evaluators. Thus impersonalism needs persons to exist before it can have any meaningful content, but it then discounts the interests those persons have once they do exist. The alternative to the person-affecting approach is therefore untenable, and this brings us full circle back to the determination of the welfare of the potential child test as unacceptable and leaves with only the interests of actual persons to consider.

Thus parental decisions would be unrestricted by the concept of harming their future offspring as those actions are the ones which bring the offspring into existence. 
Parents would thus be able to utilise reproductive technology (including genetic modification) with only legitimate public interest limiting their actions. Of course medical providers will have obligations to the parents and parental actions will be restricted by the technological capabilities of the time. Moreover, depending on how services are provided, for example, by a public or private system, parental decisions will be limited by different constraints. What is made clear is that parental interests have primacy and can only be overridden by the interests of other existing citizens, and not by the interests of the potential offspring. This could lead to a legal presumption that parental decisions to have disabled offspring or genetically modify their offspring are in their interests and that if others want to prevent such modification going ahead, then the burden is on them to prove that there is a sufficient public interest or harm being caused to actual persons.

As we have seen, this may take a number of forms, but can be based on the harms caused directly to other persons, the fairness and distribution of resources or on the ideals a society holds. For example, we want to prevent those who sadistically want to torture people from achieving their aims, or we want to ensure that every member of society has access to services on a equal basis and so some limitations to the number of times reproductive services are accessed is imposed. Another example may be prohibiting the selection of skin colour because we do not want to exist in a more prejudiced society than we do now. All of these examples, whether to do with the harm caused to a specific individual, the fairness of healthcare access between the entire population, population control policy or because of the particular ideals a society holds are based upon the impact and effect of actions on existing actual persons. Restrictions and constraints imposed on this basis are therefore permissible and justifiable. However, depending on what form the parents' interests take, for example, human rights, will affect the strength needed of the justification and the degree to which interference can extend. 
The reform recommend here, the removal of the welfare of the (potential) child test in relation to artificial reproductive services, would clearly make the interests of the prospective parents paramount. As the parents are the ones whose interests would be fulfilled by reproduction and because it is such a major component of their lives it is fair that the decision is accepted unless it can be shown that their decision is harmful to an actual person or because it violates the standards of conduct held in the socio-political unit. A decisions as to whether parental discretion should be embodied in a human or legal right is a discussion for another time. It is clear, however, that the injustice and unfairness imposed by the welfare of the (potential) child test is untenable and should be excised as part of the process of artificial reproduction. If the actions of prospective parents do not harm anyone or violate behavioural codes then they should be free to reproduce as they wish. 